\title{
Fully Investigation of RP- HPLC Analytical Method Validation Parameters for Determination of Cefixime Traces in The Different Pharmaceutical Dosage Forms and Urine Analysis
}

\author{
Mostafa F. Al-Hakkani ${ }^{12^{*}}$, Gamal. A. Gouda', Sedky H.A. Hassan ${ }^{3}$, Osman A. Farghaly', \\ and Mahmoud M.A. Mohamed² \\ 1 Department of Chemistry, Faculty of Science, Al-Azhar University, Assiut Branch, 71524, Assiut, Egypt \\ 2 Department of Chemistry, Faculty of Science, New Valley University, El-Kharja 72511, Egypt \\ 3 Department of Botany \& Microbiology, Faculty of Science, New Valley University, El-Kharja 72511, Egypt
}

\begin{abstract}
Cefixime (Cfx) is a member of the third generation of Cephalosporin antibiotics. It used on a wide scale in prescribed antibiotic drugs as anti-infection for Gram-positive and Gram-negative microorganisms. The present study aimed to develop an HPLC method of Cfx analysis enjoyed highly linearity, repeatability, robustness, ruggedness, selectivity, rapidly, and economical to use. The chromatographic system depends on the RP- BDS column ( $250 \mathrm{~mm} \times 4.6 \mathrm{~mm} \times 5 \mu \mathrm{m}$ ). The mobile phase was prepared by mixing Methanol: Phosphate buffer $(3: 7, \mathrm{v} / \mathrm{v})$ at flow rate $1.0 \mathrm{ml} / \mathrm{min}$ with wavelength detection at 254 $\mathrm{nm}$, the temperature at $30^{\circ} \mathrm{C}$ with injection volume $20 \mu \mathrm{L}$. The method revealed that satisfied linearity regression $\mathrm{R}^{2}$ (0.9996) with repeatability (0.94\%) with DL and QL; $59.3 \mathrm{ng} / \mathrm{ml}$ and $179.8 \mathrm{ng} / \mathrm{ml}$ respectively. The method showed successful and satisfying results for Cfx in bulk and pharmaceutical formulations and urine samples at low levels.
\end{abstract} Keywords: Validation, Pharmaceuticals, Cefixime, Detection limit, Quantitation limit

\section{INTRODUCTION}

The IUPAC name of $\mathrm{Cfx}$ is (6R,7R)-7-[[(2Z)-2-(2-amino-1,3-thiazol-4-yl)2(carboxymethoxyimino)acetyl] amino]-3-ethenyl-8-oxo-5-thia-1-azabicyc-

Corresponding author: Mostafa El Hakkani Authors contacts:

Gamal. A. Gouda: ggouda73@azhar.edu.eg

Sedky H.A. Hassan: sedkyhassan@scinv.au.edu.eg

Osman A. Farghaly: othman15@yahoo.com

Mahmoud M.A. Mohamed: mmhm802004@gmail.com 
lo[4.2.o]oct-2ene-2-carboxylic acid ${ }^{1}$. Cfx is a member of the third generation of the Cephalosporin antibiotics. It was derived semi-synthetically from the marine fungus Cephalosporium acremonium. Cfx contains the Cephalosporins $\beta$-lactam core ring as shown in Figure 1 A, B.

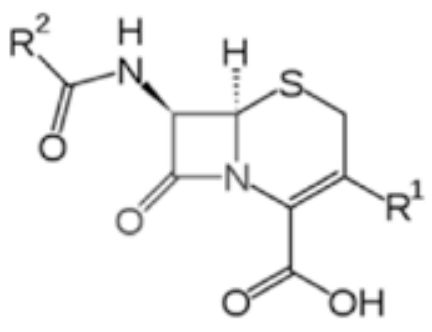

A

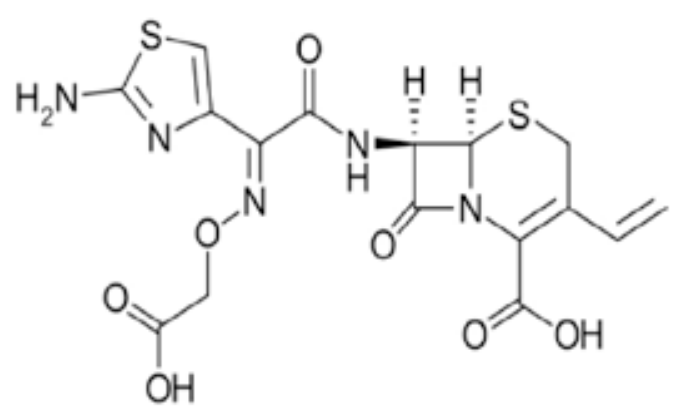

B

Figure 1. Structure of Cephalosporins $\beta$-lactam core ring (A) and Cefixime (B)

It used to treat many and various bacterial infections and it has excellent activity against many pathogens as, Enterobacteriaceae, Anaerobes, Gram-negative class such as Haemophilus influenzae, Branhamella Catarrhalis, Escherichia coli, Neisseria gonorrhoeae, klebsiella, Serratia marcescens, Haemophilus, Providencia, and Meningococcus including strains of $\beta$-lactamase producing. It is the best oral antibiotic for switch therapy due to its safety profile, high efficacy. Additionally, it has an inexpensive nature ${ }^{2}$. It works by killing bacteria and it has an analytically and clinically significant due to its broad spectrum as stability and antimicrobial activity ${ }^{3}$. Cfx is used for the reduction of the development of drugresistant bacteria. It is introducing under different finished products; a powder for oral suspension, capsules, and tablets 4 .

Several analysis methods have been developed to determine Cfx in different pharmaceutical dosage forms. These methods include different analysis techniques as microbiological methods and high-performance liquid chromatography (HPLC) 5 .

Cfx has been quantitatively analyzed in bulk materials and different pharmaceutical dosage forms by Spectrofluorimetric ${ }^{6-8}$, Spectrophotometric determination ${ }^{9-11}$ Colourimetry, HPLC by capillary electrophoresis ${ }^{12}$, Voltammetric determination ${ }^{13-15}$, HPLC-MS; mass spectrometric methods may have the highest sensitivity, but the determination process is complicated to use and very expensive ${ }^{2,16}$. 
Chromatographic separation technique is one of the most convenient, essential, easiest, and powerful in most qualitative and quantitative analysis. HPLC is currently the most satisfying tool for excellent and optimum separation ${ }^{5,17-19}$.

In the present study, an HPLC method with a photodiode array detector (PDA) was developed for the determination of the lower concentration of Cfx in different pharmaceutical dosage forms. The proposed analytical method of Cfx was found to be precise, repeatable, linear, accurate, rugged, robust, specific, selective, and economic.

\section{METHODOLOGY}

Cfx standard (99.7\%) was supplied by Covalent laboratories PVT.LTD (India) as a gift sample from Smart pharma (Assuit, Egypt). Methanol HPLC-grade, Sodium dihydrogen phosphate, Hydrochloric acid, Phosphoric acid 85\%, Sodium hydroxide, and Hydrogen peroxide (Scharlau, Spain). Deionized water used in the analysis was prepared by reverse osmosis and passed through a $0.45 \mu \mathrm{m}$ Millipore filter (Millipore Company, USA) before use. Phosphate buffer was prepared by weighing about $16.8 \mathrm{~g}$ of sodium dihydrogen phosphate and $0.5 \mathrm{ml}$ of phosphoric acid $85 \%$ in $700 \mathrm{ml}$ deionized water.

\section{Chromatographic system configuration}

Cfx was measured using the LC-20A HPLC instrument with the PDA (Shimadzu, Japan). The method was conducted using the RP BDS column (250 mm x $4.6 \mathrm{~mm}$ $\mathrm{x} 5 \mu \mathrm{m}$ ) (Thermo Scientific, USA). The mobile phase was prepared at the ratio "Methanol: Phosphate buffer" (3:7, v/v) at flow rate $1.0 \mathrm{ml} / \mathrm{min}$ with wavelength detection at $254 \mathrm{~nm}$ with column oven $30^{\circ} \mathrm{C}$ and injection volume $20 \mu \mathrm{L}$.

\section{Parameters of method validation}

The validation of the HPLC method was carried out according to International Conference on Harmonization (ICH), Food and Drug Administration (FDA), United States of American Pharmacopoeia (USP) and European Pharmacopoeia (EP) guidelines concerning parameters including tuning system and suitability of the system, Range linearity, detection limit, quantification limit, repeatability, recovery and accuracy, robustness, ruggedness, the stability of the solution, specificity and selectivity ${ }^{20-25}$.

\section{Tuning and suitability of the system}

The performance of the chromatographic system comes first. So, the instrument performance was checked at a standard tuning solution was prepared in the mobile phase at a concentration of $2.0 \mu \mathrm{g} / \mathrm{ml}$. 


\section{Range \& linearity}

It was said the method is linear if there is a good proportion between the response and working concentration starting from the lowest point in the tested range and the highest point and the $\mathrm{R}^{2}$ should be $\geq 0.999^{20-24}$.

Regression linearity equation:

$\mathbf{Y}=\mathbf{a} \mathbf{X}+\mathbf{b}$

Where, $\mathrm{Y}=$ Peak area, $\mathrm{X}=$ Concentration (\%), $\mathrm{a}$ is the slope and $\mathrm{b}$ is the intercept. Linearity was conducted using different five concentrations (50\%-150\%) of the Cfx standard. The working concentrations were prepared as, 1.0, 1.6, 2, 2.4, and $3.0 \mu \mathrm{g} / \mathrm{ml}$ using the mobile phase as a solvent. The later solutions were injected in triplicates.

\section{Detection limit (DL)}

It was defined as the minimum concentration of the analyte in the matrix that can be distinguished using the instrument detector. Additionally, it should not be represented in the precision and linearity range ${ }^{20-24}$.

\section{Quantitation limit (QL)}

It was defined as the minimum concentration of the analyte in the matrix that can be distinguished using the instrument detector. On the contrary to the detection limit, it should be represented in the precision and linearity range ${ }^{20-24}$.

DL and QL were calculated according to the linearity of the calibration curve and its standard error according to the following equations:
$\mathrm{DL}=3 \cdot 3 \sigma / S$ (2)
$Q L=10 \sigma / S$

Where $\sigma$ : is the standard error and S: is a slope of the linearity calibration curve.

\section{Accuracy and recovery}

Recovery and accuracy, each of them are used interchangeably. The accuracy of the measurement is defined as the closeness of the actual concentration (measured value) to the theoretical concentration (true value) ${ }^{20-24}$.

Accuracy and recovery were conducted using the addition of three sets of Cfx standard to the in-active ingredient of the drug to give concentration at $(1.6 \mu \mathrm{g} / \mathrm{ml}),(2.0$ $\mu \mathrm{g} / \mathrm{ml})$, and $(2.4 \mu \mathrm{g} / \mathrm{ml})$. recovery estimation was linearity equation dependent:

Recovery \%= Act. Conc.\% / Th. Conc.\% x 100 (4) 


\section{Repeatability and precision}

Repeatability was conducted using 6 different preparations of the concentration $(2.0 \mu \mathrm{g} / \mathrm{ml})$ of Cfx by the same analyst on the same day using the same equipment 20-24.

\section{Robustness}

Robustness was investigated using conscious small changes including the slight diversity in the temperature, composition of the mobile phase, etc ${ }^{20-24}$.

Changes were involved in a different organic solvent ratio (Methanol) at $( \pm 10 \%)$ and different temperature $\pm 2^{\circ} \mathrm{C}$.

\section{Ruggedness}

Ruggedness was investigated using conscious and major observable changes including analyst- analyst, column- column, and day- day with maintaining on the rest of experimental parameters and conditions at a constant rate.

\section{Stability of solution}

This test was conducted via performing the test at the target concentration of $(2.0 \mu \mathrm{g} / \mathrm{ml})$. It was measured over 12 working hours to assess the stability of the solution.

\section{Specificity and selectivity}

It can be defined as the measuring of the analyte in the presence of its degradants or interferences interpreted the connotation of specificity ${ }^{20-24}$.

- Acid hydrolysis: It was conducted using $\mathrm{HCl} 0.1 \mathrm{~N}$ for 5 minutes.

- Oxidation hydrolysis: It was conducted using $\mathrm{H}_{2} \mathrm{O}_{2} 3 \% w t / v$ for 5 minutes.

\section{Test of the validated method}

Cfx analysis in the different commercial dosage forms in the Egyptian local market

Suprax $200 \mathrm{mg}$ capsules, Suprax $100 \mathrm{mg} / 5 \mathrm{ml}$ powder for oral suspension, and Cefipharmart $400 \mathrm{mg}$ dispersible tablet for oral suspension were be tested using the validated method of Cfx.

\section{Cfx traces analysis in the different urine samples}

The method was tested for identification and quantitative analysis for 4 different urine samples. 


\section{RESULTS AND DISCUSSION}

\section{Tuning and suitability of the system}

Cefixime peak was stated about at 7.8 minutes as revealed in Figure 2. Table 1 showed a good performance for the selected method parameters where the RSD $\%<2.0 \%{ }^{20-24}$.

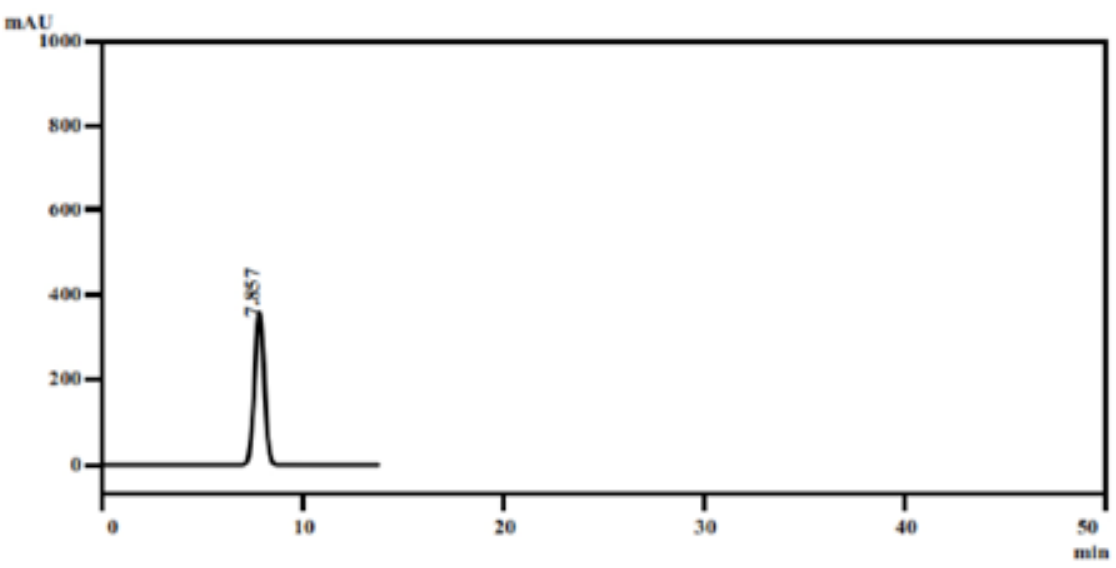

Figure 2. Cfx chromatogram

Table 1. Tuning and suitability of the system

\begin{tabular}{cccc}
\hline Replicate \# & P. A & Tailing & Plates \\
\hline 1 & 4651 & 1.221 & 12521 \\
2 & 4655 & 1.223 & 12565 \\
3 & 4658 & 1.218 & 12476 \\
4 & 4630 & 1.216 & 12515 \\
5 & 4684 & 1.218 & 12542 \\
6 & 4628 & 1.218 & 12548 \\
RSD $\%$ & $0.44 \%$ & $0.21 \%$ & $0.25 \%$ \\
\hline
\end{tabular}




\section{Range and linearity}

The results revealed high linearity " $\mathrm{R}^{2}=0.9996$ " in between the working concentration range (50 \%-150 \%) as we can see in Figure 3 and Table 2.

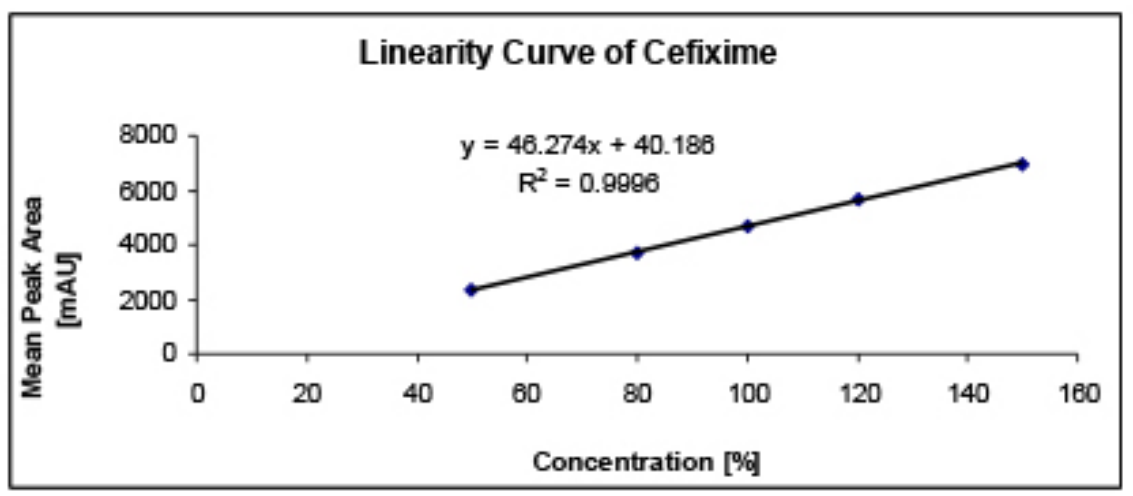

Figure 3. Linearity calibration curve of Cfx

Table 2. Range and linearity

\begin{tabular}{cccc}
\hline Conc $\%$ & Average P. As & \multicolumn{2}{c}{ Statistical data } \\
\hline $50 \%$ & 2351 & $\mathrm{R}^{2}$ & 0.9996 \\
$80 \%$ & 3705 & Slope & 46.274 \\
$100 \%$ & 4702 & Intercept & 40.186 \\
$120 \%$ & 5632 & Standard error & 41.60657 \\
$150 \%$ & 6948 & & \\
\hline
\end{tabular}

\section{DL and QL}

DL and QL limits were determined simply using the linearity calibration data of Cfx. DL was found to be $59.3 \mathrm{ng} / \mathrm{ml}$ where QL was $179.8 \mathrm{ng} / \mathrm{ml}$. 


\section{Accuracy and recovery}

Table 3. Revealed satisfaction results for recovery and accuracy within the tested range (80$120 \%$ from the target concentration).

Table 3. Accuracy and recovery

\begin{tabular}{llll}
\hline Theoretical conc\% & Average P. As & Actual conc\% & Recovery \% \\
\hline $80 \%$ & 3798 & $81.2 \%$ & $101.5 \%$ \\
$100 \%$ & 4715 & $101.0 \%$ & $101.0 \%$ \\
$120 \%$ & 5539 & $118.8 \%$ & $99.0 \%$ \\
\hline
\end{tabular}

\section{Repeatability and precision}

The RSD\% of Peak areas was used for judgment on the repeatability of the analyte using six different preparations at the same concentration as in Table 4. It was found to be $0.94 \%$ as it demanded in repeatability requirements ${ }^{20-24}$.

Table 4. Repeatability and precision

\begin{tabular}{cccc}
\hline$\#$ & Sample P. A & \multicolumn{2}{c}{ Statistical data } \\
\hline 1 & 4605 & Average P. As & 4622.333 \\
2 & 4670 & STDEV & 43.509 \\
3 & 4574 & RSD $\%$ & $0.94 \%$ \\
4 & 4590 & & \\
5 & 4614 & & \\
6 & 4681 & & \\
\hline
\end{tabular}

\section{Robustness}

The results of conscious small changes included temperature $\pm 2^{\circ} \mathrm{C}$ and organic ( $\pm 10 \%$ ) were determined using RDS \%. The RSD\% was found to be $<2 \%$ in all cases as shown in Tables 5 and 6. 
Table 5. Change in temperature results

\begin{tabular}{cccc}
\hline Replicate \# & $\begin{array}{c}\text { Set \# } \\
\mathbf{3 0}^{\circ} \mathbf{C}\end{array}$ & $\begin{array}{c}\text { Set \# } \\
\mathbf{( 3 2} \mathbf{C})\end{array}$ & $\begin{array}{c}\text { Set \# 3 } \\
\left.\mathbf{( 2 8 ^ { \circ }} \mathbf{C}\right)\end{array}$ \\
\hline 1 & 4651 & 4698 & 4616 \\
2 & 4655 & 4691 & 4605 \\
3 & 4658 & 4686 & 4594 \\
4 & 4630 & 4712 & 4587 \\
5 & 4644 & 4674 & 4621 \\
6 & 4628 & 4695 & 4600 \\
Pooled mean & & 4646.944 & \\
\hline
\end{tabular}

Table 6. Change in organic ratio results

\begin{tabular}{cccc}
\hline Replicate \# & $\begin{array}{c}\text { Set \# } \mathbf{~} \\
\mathbf{3 0 0} \mathbf{~ m l}\end{array}$ & $\begin{array}{c}\text { Set \# 2 } \\
\mathbf{3 3 0 ~} \mathbf{~ I}\end{array}$ & $\begin{array}{c}\text { Set \# 3 } \\
\mathbf{2 7 0 ~} \mathbf{~ I ~}\end{array}$ \\
\hline 1 & 4651 & 4777 & 4574 \\
2 & 4655 & 4779 & 4545 \\
3 & 4658 & 4786 & 4596 \\
4 & 4630 & 4751 & 4550 \\
5 & 4644 & 4758 & 4558 \\
6 & 4628 & 4735 & 4555 \\
Pooled mean & & 4657.222 & \\
Pooled RSD\% & & $1.86 \%$ & \\
\hline
\end{tabular}




\section{Ruggedness}

The results of conscious major and observable changes including analyst-analyst, column-column, and day-day. Data were be presented as shown in Tables 7-9. RSD \% found to be $<2 \%$ in all cases ${ }^{20-24}$.

Table 7. Day-to-day precision results

\begin{tabular}{cccc}
\hline Replicate \# & $\begin{array}{c}\text { Set \# } \\
\text { First day }\end{array}$ & $\begin{array}{c}\text { Set \# 2 } \\
\text { Second day }\end{array}$ & $\begin{array}{c}\text { Set \# 3 } \\
\text { Third day }\end{array}$ \\
\hline 1 & 4651 & 4718 & 4798 \\
2 & 4655 & 4733 & 4718 \\
3 & 4658 & 4735 & 4742 \\
4 & 4630 & 4728 & 4757 \\
5 & 4684 & 4749 & 4811 \\
6 & 4628 & 4725 & 4774 \\
Pooled mean & & 4716.333 & \\
\hline
\end{tabular}

Table 8. Analyst-to-Analyst precision results

\begin{tabular}{cccc}
\hline Replicate \# & Analyst 1 & Analyst 2 & Analyst 3 \\
\hline 1 & 4651 & 4581 & 4611 \\
2 & 4655 & 4580 & 4625 \\
3 & 4658 & 4572 & 4687 \\
4 & 4630 & 4588 & 4628 \\
5 & 4684 & 4510 & 4601 \\
6 & 4628 & 4529 & 4681 \\
Pooled mean & & 4616.611 & \\
Pooled RSD\% & & $1.09 \%$ & \\
\hline
\end{tabular}


Table 9. Column-to-Column precision results

\begin{tabular}{ccc}
\hline Replicate \# & Column \#1 & Column \#2 \\
\hline 1 & 4651 & 4752 \\
2 & 4655 & 4758 \\
3 & 4658 & 4747 \\
4 & 4630 & 4792 \\
5 & 4684 & 4772 \\
6 & 4628 & 4764 \\
Pooled mean & & \\
Pooled RSD\% & & 4707.583 \\
\hline
\end{tabular}

\section{Stability of solution}

The experimental results guided us that the tested solution of Cfx can be given repeatable and precise data over 12 hours at room temperature as in Table 10.

Table 10. Stability of solution

\begin{tabular}{cccccccc}
\hline$\#$ & O hour & $\mathbf{3}$ hours & $\mathbf{6}$ hours & $\mathbf{1 2}$ hours & $\begin{array}{c}\text { Average } \\
\text { P. As }\end{array}$ & STDEV & RSD\% \\
\hline Test P. A & 4703 & 4568 & 4661 & 4575 & 4626.8 & 66.123 & $1.43 \%$ \\
\hline
\end{tabular}

\section{Specificity and selectivity}

The current method supplied us with highly specific information about the resolution and separation performance of the nearest co-eluted peaks with a resolution parameter at least 5.2 as in Figure 4 A, B. 

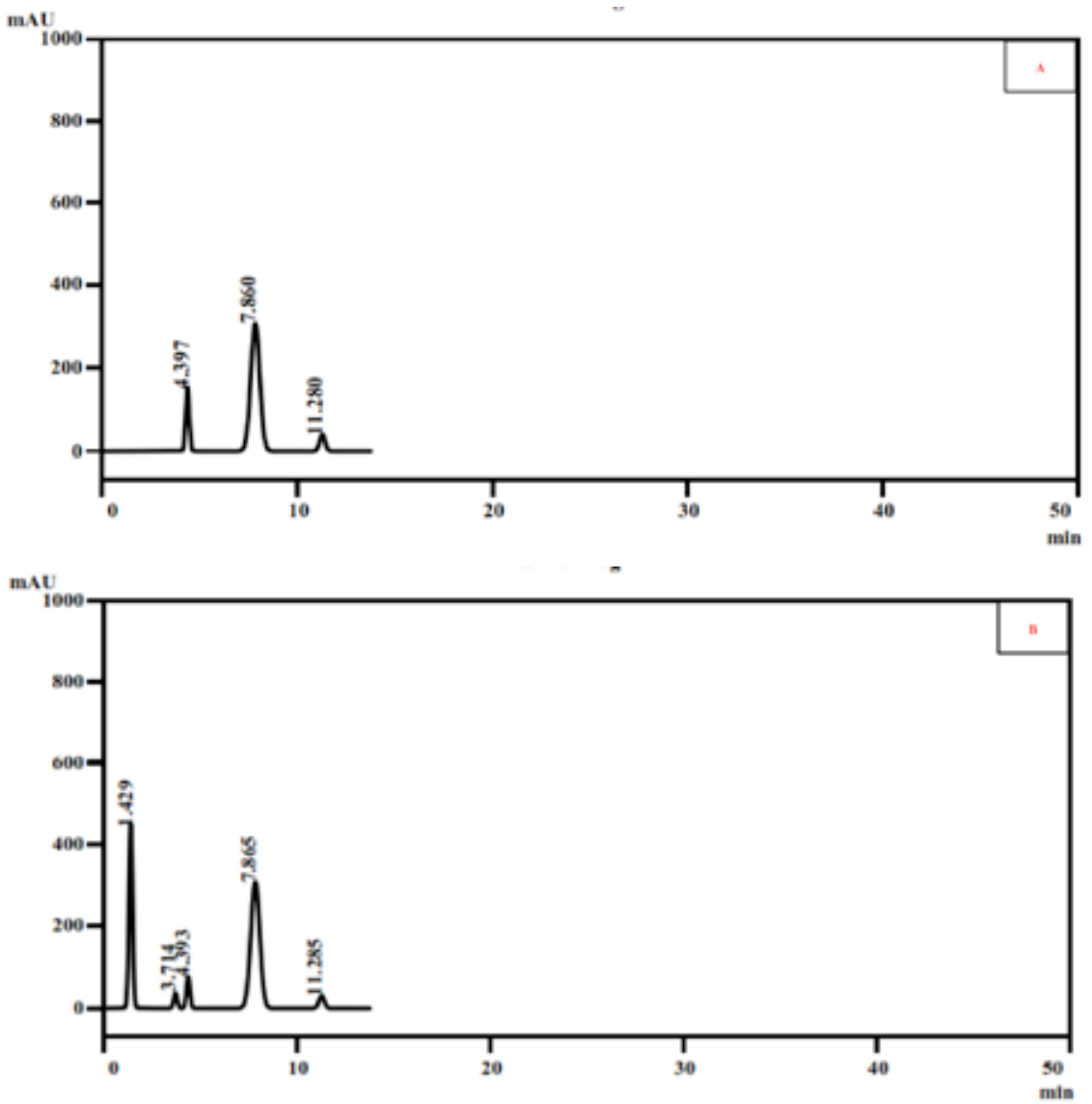

Figure 4. Effect of acid degradation $(A)$ and $\mathrm{H}_{2} \mathrm{O}_{2}$ degradation (B) in specificity test

\section{Test of the validated method}

Cfx analysis in the different commercial dosage forms in the Egyptian local market

The Cfx average assay results of Suprax $200 \mathrm{mg}$ capsules, Suprax $100 \mathrm{mg} / 5 \mathrm{ml}$ powder for oral suspension, and Cefipharmart $400 \mathrm{mg}$ dispersible tablet for oral suspension revealed good results; $103.5 \%, 101.8 \%$, and $104.4 \%$ respectively.

\section{Cfx traces analysis in the different urine samples}

The method was succeeded in Cfx traces analysis at low concentrations reached $77.6,98.1,199.5,260.7 \mathrm{ng} / \mathrm{ml}$.

The current method introduces a sensitive, rapid, easy, economical, and accurate method of Cfx analysis. The method revealed a good behavior as linear, precise 
(repeatable), robust, rugged, selective, and specific as the resolution factor between Cfx peak and any adjacent peak at least anyway > 1.5. DL and QL also, evaluated and showed an appreciated and satisfying value as $59.3 \mathrm{ng} / \mathrm{ml}$ and $179.8 \mu \mathrm{g} / \mathrm{ml}$ respectively. So, the analysis method is valid to use for Cfx determination at the minimum level of concentrations with convenient tools of analysis. The validated method gave satisfying results for the practical application of $\mathrm{Su}$ prax and Cefipharmart assay determination for three different dosage forms as revealed in the results. Also, the method showed a good result to investigate and quantitative analysis against urine samples at low concentration levels.

\section{ACKNOWLEDGEMENT}

The corresponding author gratefully acknowledges the Academy of Scientific Research \& Technology (ASRT), Egypt, Grant No. 6371 under the project Science Up., UP pharma industrial, Al-Esraa pharmaceutical optima industrial, Bio-Med industrial, and Smart pharma for pharmaceuticals for their valuable supports.

\section{CONFLICT OF INTEREST}

The authors declare that there is no conflict of interest regarding the publication and dissemination of the information provided here.

\section{ABBREVIATIONS}

Cfx Cefixime

HPLC High- performance liquid chromatography.

PDA Photodiode array detector

UV Ultraviolet

EP European Pharmacopeia

USP United States Pharmacopeia

DL Detection limit

QL Quantitation limit

Conc Concentration

P. A Peak area

P. As Peak areas

STDEV Standard deviation

RSD Relative standard deviation

Th. Theoretical 


\section{REFERENCES}

1. Gonzalez-Hernandez, R.; Nuevas-Paz, L.; Soto-Mulet, L.; López-López, M.; Hoogmartens, J. Reversed phase high performance liquid chromatographic determination of cefixime in bulk drugs. J Liq Chromatogr Relat Technol 2001. 24, 2315-2324.

2. Attimarad, M. V.; Alnajjar, A. O. A conventional HPLC-MS method for the simultaneous determination of ofloxacin and cefixime in plasma: Development and validation. $J$ Basic Clin Pharm 2013. 4, 36-41.

3. Maheshwari, M. L.; Memon, A. A.; Memon, S.; Mughal, U. U. R.; Dayo, A.; Memon, N.; Ghoto, M. A.; Leghari, M. K. Optimization of HPLC method for determination of cefixime using 2-thiophenecarboxaldehyde as derivatizing reagent: A new approach. Saudi Pharm $J$ 2015. 23, 444452 .

4. Elias, B.; Alfeen, A. Determination of cefuroxime axetil and cefixime trihydrate in pharmaceutical dosage forms by RP-HPLC method. J Pharm Anal Chem 2016. 2, 1-5.

5. Pehourcq, F.; Jarry, C. Determination of third-generation cephalosporins by high-performance liquid chromatography in connection with pharmacokinetic studies. $J$ Chromatogr A 1998. $812,159-178$.

6. Bukhari, N.; Al-Warthan, A. A.; Wabaidur, S. M.; Othman, Z. A.; Javid, M.; Haider, S. Spectrofluorimetric determination of cefixime in pharmaceutical preparation and biological fluids using calcein as a fluorescence probe. Sens Lett 2010. 8, 280-284.

7. Shah, J.; Jan, M. R.; Shah, S. Spectrofluorimetric method for determination and validation of cefixime in pharmaceutical preparations through derivatization with 2-cyanoacetamide. J Fluoresc 2011. 21, 579-585.

8. El Walily, A. F. M.; Gazy, A. A. K.; Belal, S. F.; Khamis, E. F. Use of cerium (IV) in the spectrophotometric and spectrofluorimetric determinations of penicillins and cephalosporins in their pharmaceutical preparations. Spectrosc Lett 2000. 33, 931-948.

9. Al-Momani, I. Spectrophotometric determination of selected cephalosporins in drug formulations using flow injection analysis. $J$ Pharm Biomed Anal 2001. 25, 751-757.

10. El-Walily, A. F. M.; Gazy, A. A.; Belal, S. F.; Khamis, E. F. Quantitative determination of some thiazole cephalosporins through complexation with palladium (II) chloride. $J$ Pharm Biomed Anal 2000. 22, 385-392.

11. Shankar, D.; Sushma, K.; Lakshmi, R.; Rao, Y. S.; Reddy, M.; Murthy, T. Spectrophotometric determination of cefixime trihydrate. Asian J Chem 2oo1. 13, 1649-1651.

12. Honda, S.; Taga, A.; Kakehi, K.; Koda, S.; Okamoto, Y. Determination of cefixime and its metabolises by high-performance capillary electrophoresis. J Chromatogr A 1992. 590, 364-368.

13. Golcu, A.; Dogan, B.; Ozkan, S. A. Anodic voltammetric behavior and determination of cefixime in pharmaceutical dosage forms and biological fluids. Talanta 2oo5. 67, 703-712.

14. Jain, R.; Gupta, V. K.; Jadon, N.; Radhapyari, K. Voltammetric determination of cefixime in pharmaceuticals and biological fluids. Anal Biochem 2010. 407, 79-88.

15. Reddy, T. M.; Sreedhar, M.; Reddy, S. J. Voltammetric behavior of Cefixime and Cefpodoxime Proxetil and determination in pharmaceutical formulations and urine. $J$ Pharm Biomed Anal 2003. 31, 811-818.

16. Wen-Y, T.; Zhen-Yu, Q.; Heng, Z. Determination of cefixime in human plasma by HPLC-MS/ MS. $J$ Chin Mass Spectrom Soc 2008. 29, 211-212.

17. Bhinge, S. D.; Malipatil, S. M.; Sonawane, L. V.; Chittapurkar, H. R. Simultaneous Estimation 
of Cefixime and Dicloxacillin in Bulk and Tablet Formulation by RP-HPLC Method. FABAD $J$ Pharm Sci 2012. 37, 63-71.

18. Patel, S. A.; Patel, J. V. Rp-HPLC method for simultaneous estimation of cefixime trihydrate and linezolid in tablet dosage form. Int J Pharm Biol Sci 2013. 3, 372-379.

19. Saddik, M.S.; Alsharif, F.M.; El-Mokhtar, M.A.; Al-Hakkani, M.F.; El-Mahdy, M.M.; Farghaly, H.S.; Abou-Taleb, H.A. Biosynthesis, Characterization, and Wound-Healing Activity of Phenytoin-Loaded Copper Nanoparticles. AAPS PharmSciTech 2020. 21, 1-12. https://doi. org/10.1208/s12249-020-01700-5.

20. Al-Hakkani, M. F. A rapid, developed and validated RP-HPLC method for determination of azithromycin. SN Appl Sci 2019. 1, 222. https://doi.org/10.1007/s42452-019-0237-6

21. Al-Hakkani, M. F. Forced degradation study with a developed and validated RP-HPLC method for determination of cefpodoxime proxetil in the bulk and finished pharmaceutical products. J Iran Chem Soc 2019. 16, 1571-1578. https://doi.org/10.1007/s13738-019-01630-5

22. Al-Hakkani, M. F. Guideline of inductively coupled plasma mass spectrometry "ICP-MS": fundamentals, practices, determination of the limits, quality control, and method validation parameters. SN Appl Sci 2019. 1, 791. https://doi.org/10.1007/s42452-019-0825-5

23. Al-Hakkani, M.F. HPLC Analytical Method Validation for Determination of Cefotaxime in the Bulk and Finished Pharmaceutical Dosage Form. Sustainable Chem Eng 2o2o. 1, 33-42. https://doi.org/10.37256/sce.112020199.33-42.

24. Al-Hakkani, M.F. Biogenic copper nanoparticles and their applications: A review, SN Appl Sci 2020. 2, 505. https://doi.org/10.1007/s42452-020-2279-1

25. Devaraj, S.; Sivaperuman A.; Nagarajan N.C. RP-UPLC Method Development and Validation for Simultaneous Estimation of Mometasone Furoate and Miconazole Nitrate in Semisolid Dosage Form. Acta Pharm Sci 2020. 58, 335-348. https://doi.org/10.23893/1307-2080. APS.05819 